\title{
Spatiotemporal crustal strain distribution around the Ishikari-Teichi-Toen fault zone estimated from global navigation satellite system data
}

\author{
Mako Ohzono ${ }^{1^{*}} \mathbb{0}$, Hiroaki Takahashi ${ }^{1}$ and Chihiro Ito $^{2}$
}

\begin{abstract}
Based on analyses of global navigation satellite system data since 1996, we investigate the spatiotemporal strain field around the Ishikari-Teichi-Toen fault zone, which is a major active fault zone close to the epicenter of the 2018 Eastern Iburi earthquake in Hokkaido, Japan. Strain rates during almost whole periods, except for the timings of two distant large interplate earthquakes and following several years show an E-W to ESE-WNW contraction of 0.1 ppm/year. This strain rate is approximately an order of magnitude larger than that of the surrounding area. Strain rate disturbances due to large earthquakes diminish within several years and return to the original level, suggesting that there is a uniform strain accumulation along this fault zone. Strain rate profiles that traverse the fault zone are characterized by a major contraction, corresponding to the Ishikari lowlands where a significantly thick low seismic velocity layer exists. A relatively high strain rate around this fault zone may reflect some amount of inelastic strain accumulation in addition to the elastic strain accumulation along the faults originating from complex fault and crustal structures.
\end{abstract}

Keywords: 2018 Eastern Iburi earthquake, Ishikari lowlands, GNSS, Strain concentration zone, Active faults

\section{Introduction}

The Ishikari-Teichi-Toen Fault zone (hereafter referred to as the Ishikari fault zone) is an active fault located along the eastern edge of the Ishikari lowlands in Hokkaido, Japan (Fig. 1, Headquarters for Earthquake Research Promotion (HERP) 2018a). This zone forms part of a major geological boundary that extends in a $\mathrm{N}-\mathrm{S}$ direction and is affected by compressional tectonics as it is adjacent to the Hidaka collision belt (e.g., Kimura 1994, 1996). Seismic velocity structures (Iwasaki et al. 2004; Kita et al. 2012) and Bouguer anomalies (National Institute of Advanced Industrial Science and Technology 2018) are characterized by clear boundaries, indicating the existence of a large structural boundary in the vicinity of the fault zone.

\footnotetext{
*Correspondence: m.ohzono@sci.hokudai.ac.jp

${ }^{1}$ Institute of Seismology and Volcanology, Faculty of Science, Hokkaido University, Sapporo, Japan

Full list of author information is available at the end of the article
}

The 2018 Eastern Iburi earthquake of Mw 6.6 (F-net solution, National Research Institute for Earth Science and Disaster Resilience (NIED) 2018) was an intraplate earthquake that occurred on September 6, 2018 at southeast portion of the Ishikari fault zone. The mainshock and aftershock distribution, which was analyzed by Katsumata et al. (in review), indicates that the coseismic fault associated with the Eastern Iburi earthquake is not directly connected to the Ishikari fault zone. However, the relationship between the seismic activity and the active faults of this region requires further attention.

Regional crustal movement in Hokkaido determined from geodetic data shows that the SE-NW to ESEWNW contractional field is mainly affected by Pacific plate subduction. In addition to this regional tectonic setting, several detailed geodetic observations highlight the importance of block boundaries in the Hokkaido region. Based on data from an 80-year geodetic survey that began in the early 1900s, Hashimoto and Tada (1988) suggest that Hokkaido is separable into three blocks, 


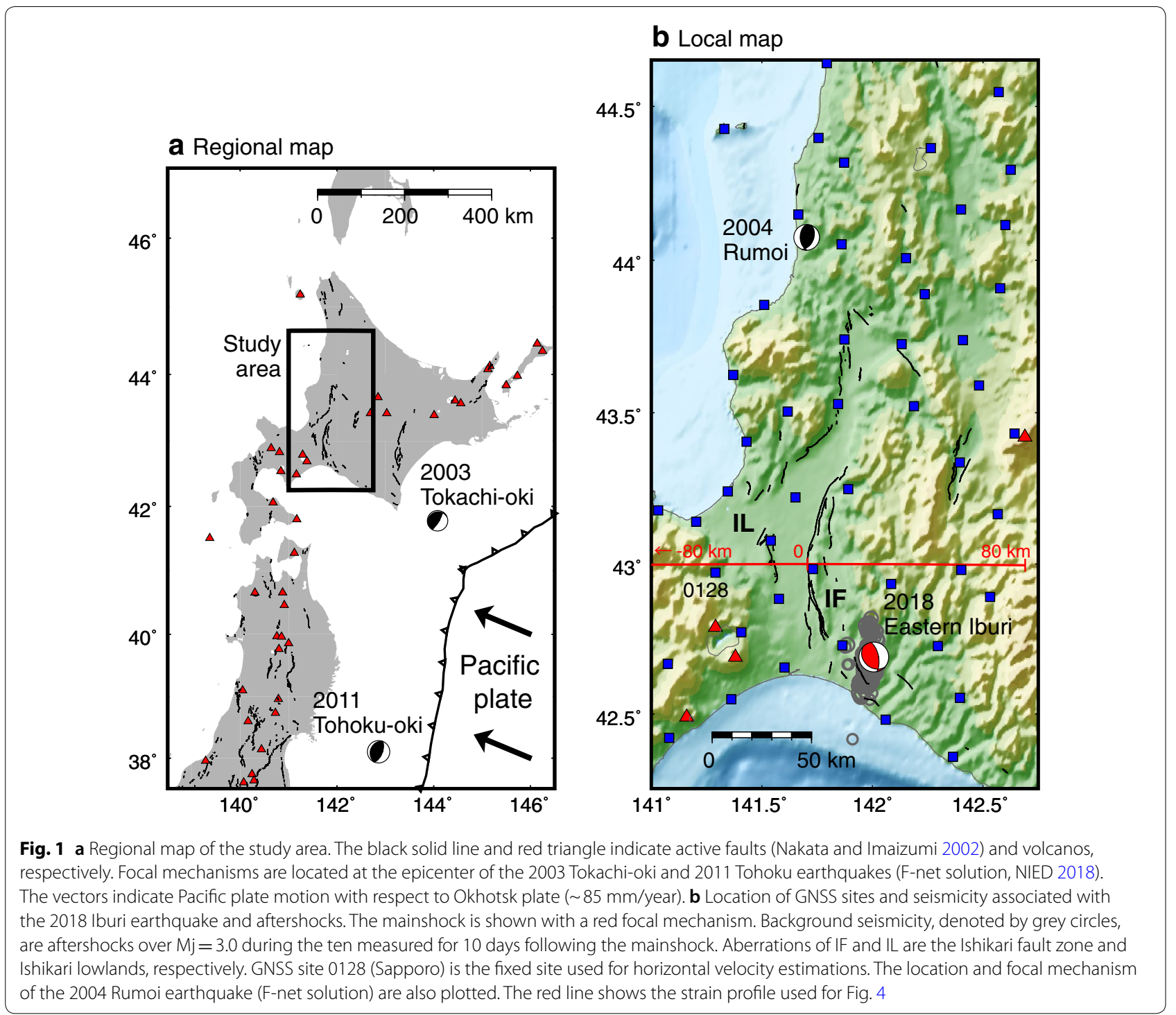

whose boundaries include the area surrounding the Ishikari fault zone. Loveless and Meade (2010) explain the crustal deformation field based on a block boundary along this fault zone using recent global navigation satellite system (GNSS) data. Therefore, this area may play a role as a locking fault or a significant deformable zone.

Strain measurement is a preferable tool to investigate internal crustal deformation. Nationwide geodetic strain distributions based on analyses of GNSS data show relatively high contractional dilatation strain rates surrounding the Ishikari lowlands and Ishikari fault zone of the order of $\sim 0.1 \mathrm{ppm} /$ year (Sagiya et al. 2000). This strain rate is comparable to other high-strain rate fields, such as the Niigata-Kobe Tectonic Zone (Sagiya et al. 2000) and Ou backbone range (Miura et al. 2004), which have experienced destructive intraplate earthquakes. In addition, these regions exhibit significant discontinuity along subsurface structures, which is a possible strain concentration mechanism (e.g., Iio et al. 2004; Hasegawa et al. 2005; Meneses-Gutierrez and Sagiya 2016; Meneses-Gutierrez et al. 2018).

Based on this background, understanding the crustal strain field around the Ishikari fault zone with high spatiotemporal resolution is important for earthquake risk assessment. Sagiya et al. (2000) discussed the comprehensive strain field of the region but only analyzed the period between 1997 and 2000. On the other hand, we are able to use an increasing number of GNSS sites and have access to longer periods of data. Therefore, we can 
conduct a more detailed analysis of the strain field surrounding this area.

In this study, we focus on the area shown in Fig. 1 and estimate the crustal strain field in detail using the last 22 years of available GNSS data. Two large and distant interplate earthquakes (i.e., the $2003 \mathrm{Mw} 8.0$ Tokachioki earthquake and the $2011 \mathrm{Mw} 9.0$ Tohoku-oki earthquake; epicenters are plotted in Fig. 1a) occurred during this 22-year period that generated co- and post-seismic deformation in the study area (e.g., Ozawa et al. 2004; Pollitz et al. 2011). Taking the occurrences of these earthquakes, we also analyze the changes in the spatiotemporal strain rate and its characteristics.

\section{Data and analysis}

In this study, we use the daily coordinates (F3 solution; Nakagawa et al. 2009) from the nationwide GNSS network (called GEONET), operated by the Geospatial Information Authority of Japan (GSI) from March 1996 to December 2017.

Comparison between the steady-state strain field during interseismic periods along the subduction zone and distant earthquakes that induced post-seismic transient strain regimes yields characteristics of long- and shortterm responses to strain accumulation in the fault zone (Meneses-Gutierrez and Sagiya 2016). However, in this study, we first focus on features associated with the accumulation of steady-state strain. To understand the strain rate field during steady-state, we estimate the strain rate field assuming two quiescent periods and considering the seismic effects from two large earthquakes: March 1996 (first day of available data) to September 2003 (before the 2003 Tokachi-oki earthquake; period 1) and January 2014 to December 2017 (after the 2011 Tohoku-oki earthquake; period 2). For period 2, postseismic deformation caused by the 2011 Tohoku-oki earthquake lasted until recently, but the coordinate time series does not show clear transient deformation during this period. Therefore, we assume that this period of postseismic effect is negligible and treat as steady-state for the present. For these two periods of coordinate time series at each site, we estimate the linear velocity component using a least-square linear fit, as well as the annual and semi-annual components. The estimated horizontal velocities are calculated as strain rate tensors by applying the method developed by Shen et al. $(1996)$ at each grid $\left(0.05^{\circ} \times 0.05^{\circ}\right)$. The distance decay constant, which controls the weighting of the observations, is assumed to be $30 \mathrm{~km}$.

We also estimate the annual strain to investigate changes in the temporal strain surrounding the study area. The annual horizontal displacement is calculated based on the differences in the averaged five-day coordinates beginning each September since 1996 and until
2018. Subsequently, the annual strain is calculated using the interpolation procedures described above (Shen et al. 1996).

\section{Results and discussion \\ Strain rate distribution during the two periods}

For the two assumed steady-state periods, their strain rate and horizontal velocity fields are shown in Fig. 2. For comparison, the regional strain rate distribution in Hokkaido is also shown (Fig. 2a-1, b-1). As shown in both local maps (Fig. 2a-2, b-2), a relatively high rate of contractional strain was observed along the Ishikari fault zone. This is comparable with the strain in eastern Hokkaido, which is strongly affected by interplate coupling from the Kurile Trench. The location of the high strain rate field roughly corresponds to the block model boundary suggested by Hashimoto and Tada (1988) as well as Loveless and Meade (2010). Here, we observe a maximum principal strain rate for the E-W to ESE-WNW contraction of $\sim 0.1 \mathrm{ppm} /$ year. This value is approximately an order of magnitude larger than the surrounding area. Near the Ishikari fault zone, the regional strain distribution estimated from GNSS data (between 1997 and 1999) (Sagiya et al. 2000) and longer periods from geodetic surveys (Hashimoto and Tada 1988; GSI 2018a) also indicate similar patterns. Therefore, this high strain rate likely dominated for more than 100 years.

Although the distribution of high strain rates is clearly visible in the study area, the spatial patterns differ between periods 1 and 2 (Fig. 2a-2, b-2). Compared with period 1 , which represents a mostly pure interseismic period, period 2 may have been affected by postseismic deformation associated with two previous large earthquakes. Since the horizontal velocity patterns also differ before and after the events (Fig. 2a-3, b-3), postseismic deformation likely affected the spatial pattern in period 2 , even if the time series is stable.

In addition, the number of GNSS sites and their geometries changed during these two periods (i.e., a total of 34 GNSS sites during period 1 increased to 47 sites during period 2 in the same region; Fig. 1b). To confirm the effect of site distribution, the same GNSS sites between periods 1 and 2 are chosen for calculation of the strain distribution around the study area (Additional file 1: Figs. S1(a) and S1(b)). As a result, different strain distribution patterns are estimated using the same sites, and each period of the pattern exhibit the same tendency as each period in Fig. 2. Therefore, the strain distribution in period 2 reflects the postseismic effect by two distant large earthquakes. However, it is clear that both periods exhibit relatively large E-W to ESE-WNW contractional strain rate fields around the Ishikari fault zone. It is likely 


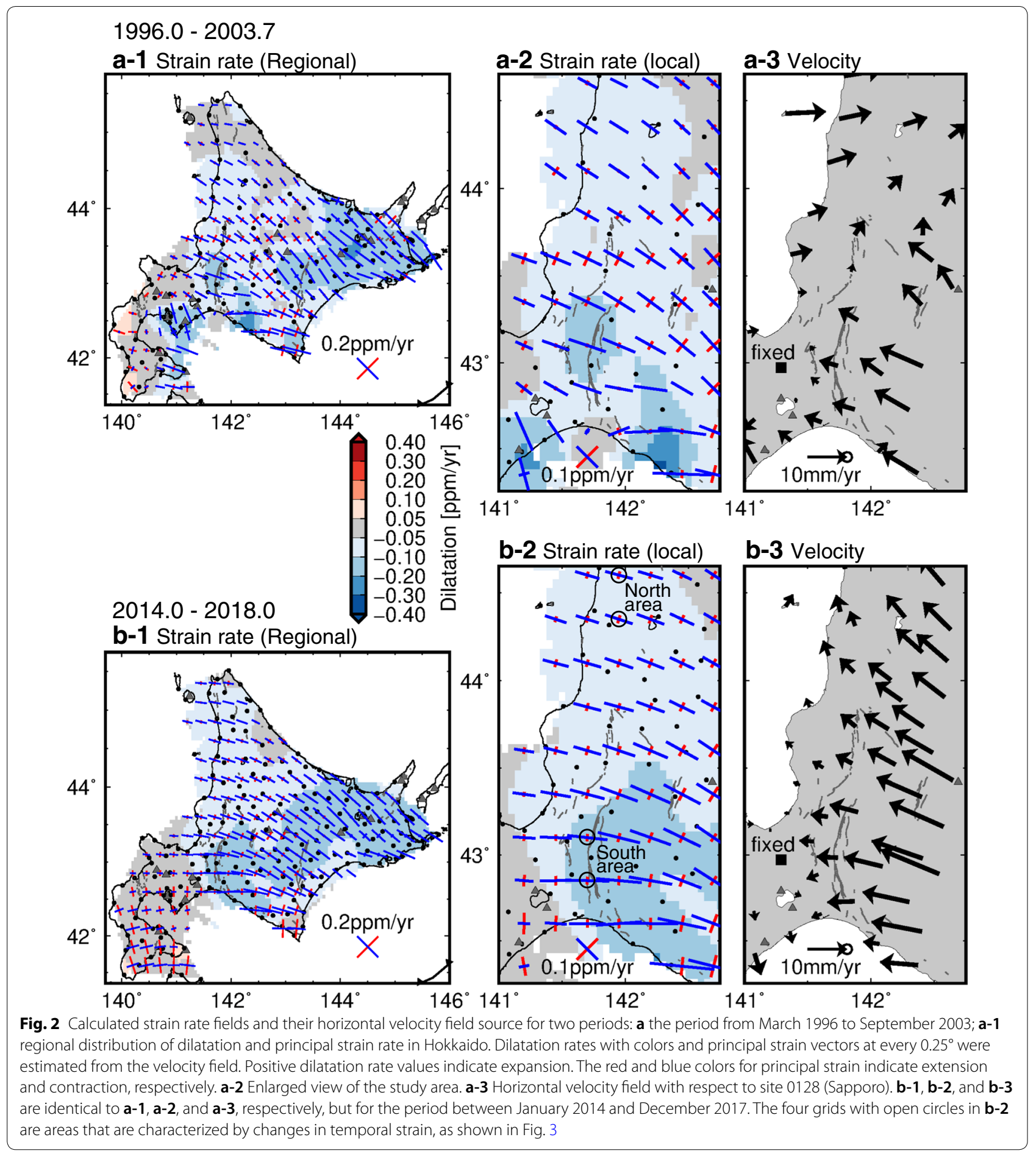

that the contractional strain in this period lasted for the same amount of time as in period 1.

\section{Temporal changes in the strain field}

Changes in the temporal strain are investigated using annual strain rates. To compare the changes in temporal strain between the vicinity of the Ishikari fault zone and other regions, two areas composed of two grids are selected (Fig. $2 \mathrm{~b}$; north: $141.95^{\circ} \mathrm{E}, 44.35^{\circ} \mathrm{N}$ and $141.95^{\circ} \mathrm{E}$, $44.60^{\circ} \mathrm{N}$ and south: $141.70^{\circ} \mathrm{E}, 42.85^{\circ} \mathrm{N}$ and $141.70^{\circ} \mathrm{E}$, $43.10^{\circ} \mathrm{N}$ ) and their dilatation and $\mathrm{E}-\mathrm{W}$ annual strain component are plotted (Fig. 3). Because of the effects 


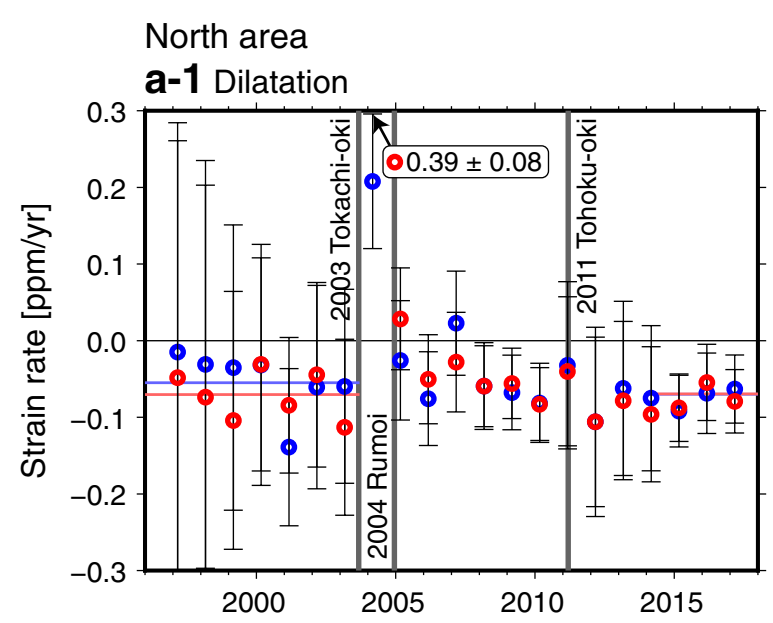

\section{a-2 E-W component}

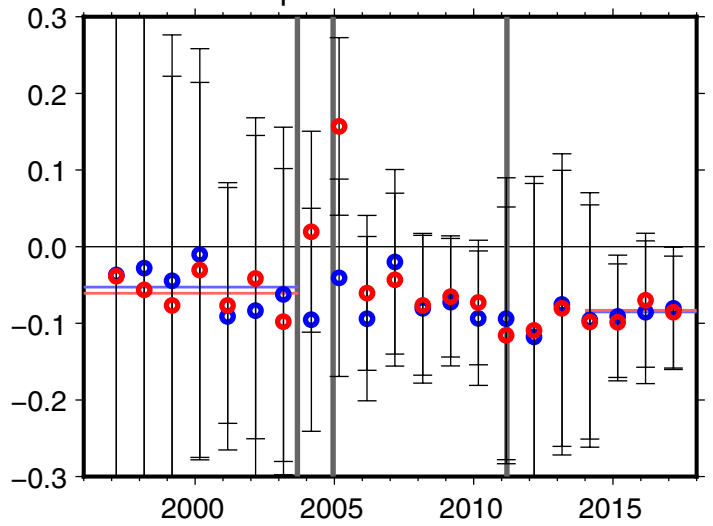

South area

b-1 Dilatation

\section{b-2 E-W component}
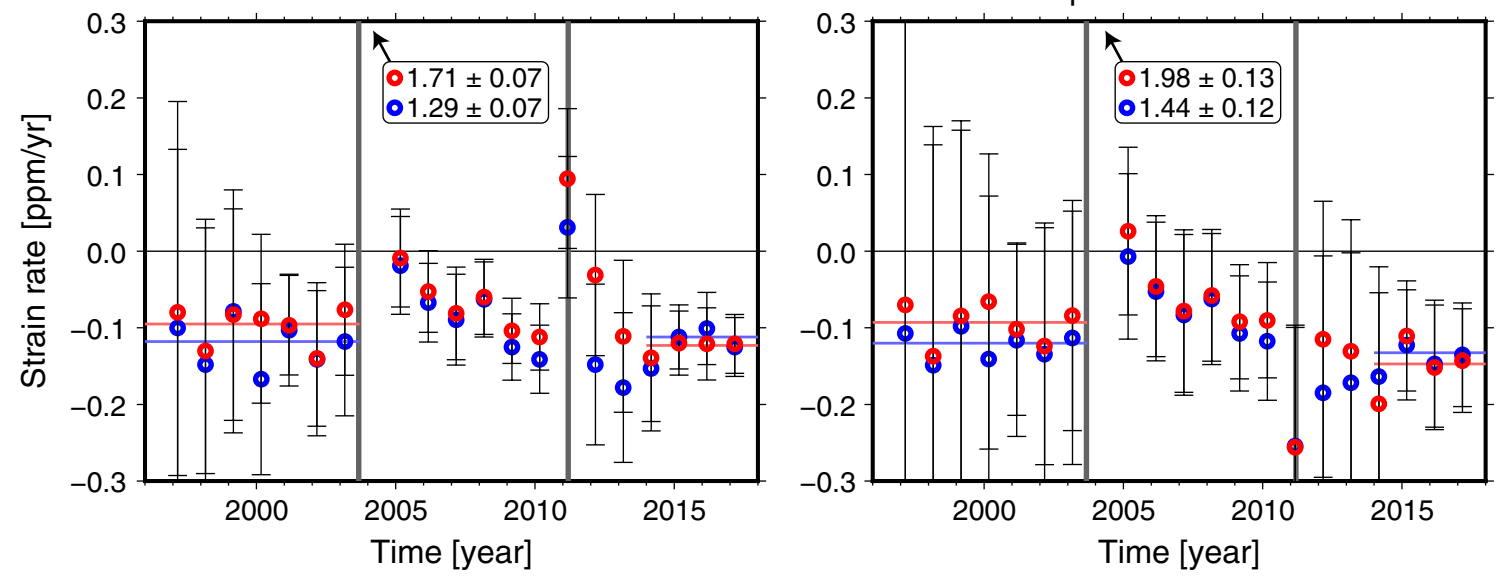

Fig. 3 Temporal changes in the strain rate: a for northern areas. a-1 Dilatation in the two northern areas (red: $141.95^{\circ} \mathrm{E}, 44.35^{\circ} \mathrm{N}$ and blue: $141.95^{\circ} \mathrm{E}$, $44.60^{\circ} \mathrm{N}$ ). Vertical bars indicate the timing of large earthquakes (i.e., the 2003 Tokachi-oki, 2011 Tohoku-oki, and 2004 Rumoi earthquakes). Error bars are $0.5-\sigma$. The horizontal colored lines behind the March 1996 to September 2003 and January 2014 to December 2017 periods are the strain rates shown in Fig. 2 estimated from the two velocity fields. Each color corresponds to a grid location. $\mathbf{a}-\mathbf{2}$ is identical to $\mathbf{a}-\mathbf{1}$ but for the E-W component. b Southern areas. b-1 and $\mathbf{b}-\mathbf{2}$ are identical to $\mathbf{a}-\mathbf{1}$ and $\mathbf{a}-\mathbf{2}$, respectively, but are for southern areas (red: $141.70^{\circ} \mathrm{E}, 42.85^{\circ} \mathrm{N}$ and blue: $141.70^{\circ} \mathrm{E}$, $\left.43.10^{\circ} \mathrm{N}\right)$

of the 2003 Tokachi-oki earthquake, we estimate a large extensional strain rate, i.e., greater than $0.3 \mathrm{ppm} /$ year, for 2003, whose values are denoted by the text in Fig. 3a-1, $\mathrm{b}-1$, and $\mathrm{b}-2$. The southern area is near the surface trace of the Ishikari fault zone, which is the focus of this study.

In the northern area (Fig. 3a), the entire estimated period is characterized by uniform E-W contractional strain of $<0.1 \mathrm{ppm} / \mathrm{year}$, except for 2003 and 2004. The 2003 Tokachi-oki earthquake and the 2004 Rumoi earthquake (Mw5.7, F-net solution, NIED 2018), which was an intraplate earthquake that occurred near the study area, induced a transient extensional strain. Effects from the 2011 Tohoku-oki earthquake are negligible. On the other hand, contractional strain in the southern area (Fig. 3b) is larger than that in the northern area throughout the entire period, at $\sim 0.1 \mathrm{ppm} /$ year, except for periods during large, distant earthquakes (i.e., in 2003 and 2011). The 2003 Tokachi-oki earthquake generated a significant amount of extensional strain similar to that observed in the northern area. After this earthquake, the values for both types of strain decreased and gradually shifted to contraction (2004-2010). Finally, contractional strain attained an identical level of $\sim 0.1 \mathrm{ppm} /$ year. During this period, which includes the 2011 Tohoku-oki earthquake, dilatational strain is characterized by extension (Fig. 3b1) while E-W strain indicates contraction (Fig. 3b-2). 
This is due to the large coseismic N-S extraction that occurred in the area. Disturbances induced by the 2011 Tohoku-oki earthquake also gradually diminish within a few years. Recent strain rates are uniform and nearly identical to those of the interseismic period (before 2003).

As a result, changes in the temporal strain exhibit relatively larger contractional strain rates near the Ishikari fault zone throughout the entire period compared to that of the northern area of the surrounding region. Coseismic and postseismic effects are observed, which diminish within several years and eventually return to the original level. Several years before the 2018 Eastern Iburi earthquake, characteristic features are not observed near the fault zone, indicating a certain accumulation of uniform contractional strain.

For the 2018 Eastern Iburi earthquake, previous studies have proposed coseismic fault models to explain less than approximately $5 \mathrm{~cm}$ of the coseismic displacement (GSI 2018b). Both the strain distributions, which are calculated from the coseismic displacement recorded on the GNSS network, and theoretical displacement field calculated from the fault model, show small E-W to ENEWSW contraction near the southern area (Fig. 3b). The value of the former is approximately 0.3 and the latter is less than approximately $0.1 \mathrm{ppm}$, respectively (Additional file 1: Figure S2). This transient change in strain may slightly affect the areas around the seismic region.

\section{Spatial patterns of strain distribution and causes of strain concentration}

The results of this study clearly show a relatively large and uniform rate of contractional strain (i.e., approximately one order of magnitude larger than the adjacent areas) surrounding the Ishikari fault zone for at least the past 20 years, even with some transient disturbances. In addition, this condition has probably lasted for a significantly longer duration (approximately 100 years) (e.g., Hashinoto and Tada 1988; GSI 2018a). To understand how the accumulated strain is released, the characteristics of the uniform spatial strain rate distributions around the Ishikari fault zone and its causes will be discussed.

A major cause of contractional strain is the elastic strain, which accumulates during interseismic periods on the fault and is released during coseismic slip. As mentioned in the previous section, effects from surrounding large interplate earthquakes, characterized by $\sim 100$-year recurrence intervals, disappear within several years. Therefore, if this elevated strain rate $(0.1 \mathrm{ppm} / \mathrm{year})$ around the Ishikari fault zone has lasted for long periods in terms of geological timescale, this effect is insignificant. On the other hand, HERP (2018b) estimated that the Ishikari fault zone has a recurrence interval of
1000-2000 years and can produce an M7.9 earthquake. If strain accumulation continues during this interval, the amount of accumulated strain could reach 100-200 ppm. Previous studies have observed extensional strain on the order of $10 \mathrm{ppm}$ for the M9-class coseismic events even if the area was $\sim 100 \mathrm{~km}$ away from the coseismic fault (Ohzono et al. 2012). It is predicted that earthquakes at the Ishikari fault zone will release this accumulated strain elastically with $>10 \mathrm{ppm}$ around this seismic region.

However, from the view of subsurface structure, this area possibly acts inelastically and exhibits smaller elasticity than the surrounding areas due to the approximately $10 \mathrm{~km}$ thick sediment layer near the fault zone (e.g., Iwasaki et al. 2004). A similar case is the Mid-Niigata region located in the Niigata-Kobe tectonic zone, which has a thick sedimentary layer. Meneses-Gutierrez et al. (2018) evaluated the surface deformation throughout this region by analyzing the geodetic strain field during pre-, co-, and post-seismic periods. Although their conclusions suggest a detachment between the upper weak zone and lower basement rock, the authors explain the localized deformation via inelastic deformation, assuming that the weak zone is in the crust and the deeper zone is characterized by aseismic fault slip.

To confirm the effects of inelastic strain, which is also affected by the thick sediment layer, we follow the approach of Meneses-Gutierrez et al. (2018) and construct E-W strain distribution profiles with a length of $160 \mathrm{~km}$ that traverse the Ishikari fault zone (across latitudes at $43.0^{\circ} \mathrm{N}$ ). Two periods of strain rate fields are used, and long-wavelength components are removed to extract the localized strain field (Fig. 4). The original strain profile shown in Fig. 4a indicates a contractional field and increases toward the east, while a large steep change around the Ishikari lowlands occurs, including the area of the Ishikari fault zone. Both period profiles that extracted localized strain (Fig. 4b), which eliminated any linear trends, correspond to a long-wavelength strain component and show significant contractional strain distribution around the Ishikari lowlands. Considering the location of the Ishikari fault zone (eastern edge of the Ishikari lowlands) and its east-dipping fault geometry (HERP 2018b), we suggest that the deeper extension of the fault, which is probably enforced loading, is located more on the eastern side. This indicates that if the obtained strain distribution only reflects the effect of elastic fault locking, the peak contractional strain is expected to concentrate east of the Ishikari fault zone. However, the observational profile shows a contractional field beneath the wide area of the Ishikari lowlands. Therefore, the contractional strain around this area is possibly caused by inelastic deformation due to the thick sediments of the Ishikari lowlands. For a more 


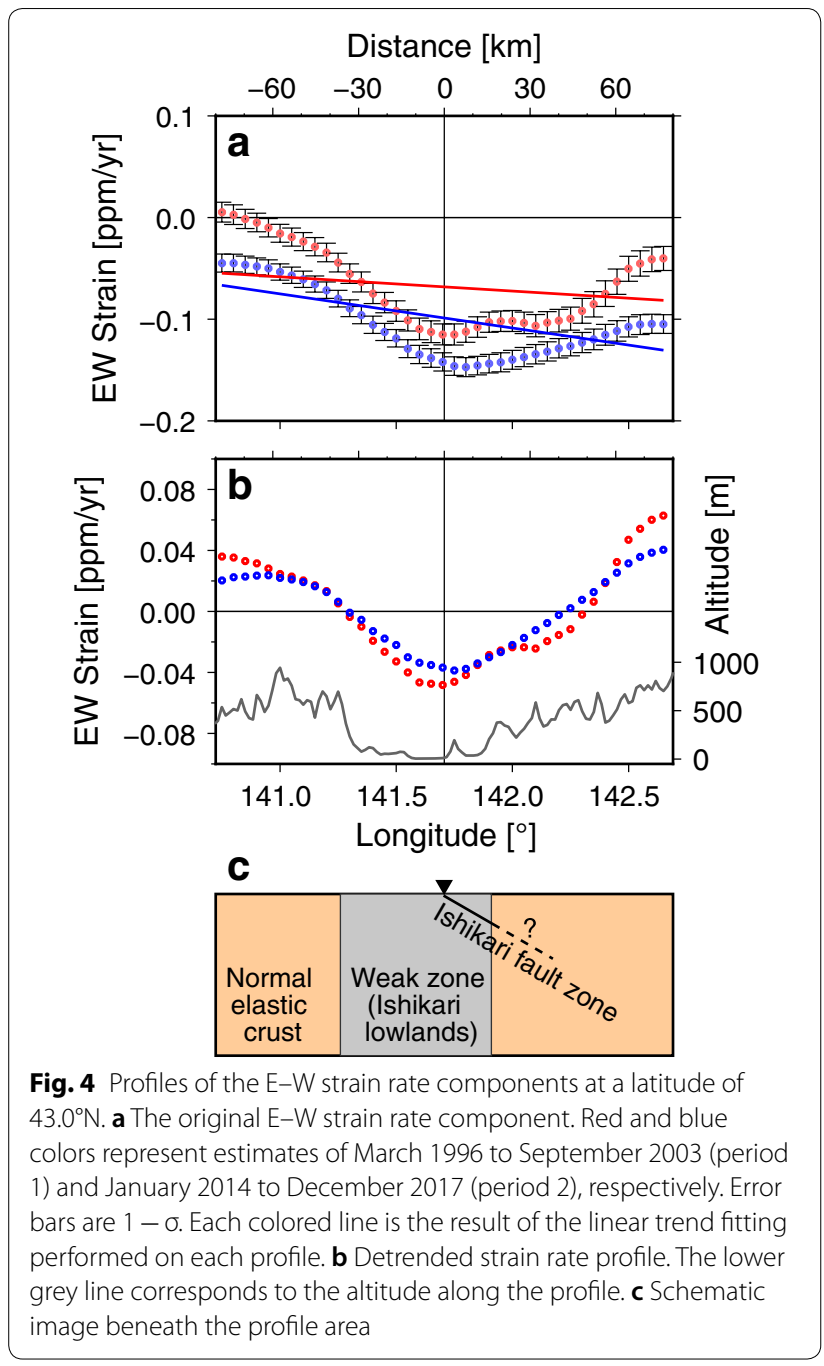

detailed discussion, we must consider crustal responses during other periods in the seismic cycle, not only interseismic periods. It is also necessary to perform careful simulations while assuming the fault geometry of deeper regions, as well as the elasticity of subsurface structures and the inelastic effect beneath the Ishikari lowlands quantitively. However, this strain distribution pattern might be affected by the inelastic strain effect of in the Ishikari lowlands, in addition to the elastic strain accumulation on the Ishikari fault zone.

The 2018 Eastern Iburi earthquake was a relatively deep intraplate earthquake. Therefore, it is difficult to directly discuss stress accumulation and release processes based on GNSS data because it is indicative of only the surface strain field. However, the high strain rate field is distributed around the focal area. Therefore, we must consider the relationship between this strain concentration zone and mechanisms that induce accumulation of deeper stress and/or release processes in the future.

\section{Conclusions}

In this study, we confirmed the occurrence of relatively large strain concentrations surrounding the Ishikari fault zone using the last 22 years of GNSS data. Temporal changes in strain for this area indicate uniform contractional strain that is larger than the surrounding areas, except for several disturbances due to previous large earthquakes. The spatial strain distribution patterns show a major contractional strain field centered around the Ishikari lowlands including the area of the Ishikari fault zone. This pattern likely indicates that the causes of strain concentration in this area involve elastic strain accumulation along the fault zone and inelastic contraction due to a weak crustal layer near the fault zone.

\section{Additional file}

Additional file 1: Figure S1. Horizontal velocity and strain distribution using same GNSS sites in (a) period 1 and (b) period 2. Figure S2. Coseismic strain field at the 2018 Eastern Iburi earthquake. (a) Observed displacement from GEONET (i.e., the difference between averaged threeday coordinates before and after the event) and the corresponding strain field. (b) Theoretical displacement estimated using data from GSI (2018b) and the corresponding strain field.

\section{Authors' contributions}

$\mathrm{MO}$ analyzed the GNSS data and made major contributions to the manuscript. HT and $\mathrm{Cl}$ joined the discussion. All authors read and approved the manuscript.

\section{Author details}

${ }^{1}$ Institute of Seismology and Volcanology, Faculty of Science, Hokkaido University, Sapporo, Japan. ${ }^{2}$ Institute of Seismology and Volcanology, Graduate School of Science, Hokkaido University, Sapporo, Japan.

\section{Acknowledgements}

GNSS data were provided by the GSI. Hypocenter data and mechanisms were obtained from the JMA and NIED. All figures were drawn using the General Matting Tools (Wessel et al. 2013). We would like to thank the anonymous reviewer and Dr. Takuji Yamada proving very useful comments and suggestions for improving our manuscript.

\section{Competing interests}

The authors declare that they have no competing interests.

\section{Availability of data and materials}

The datasets used and/or analyzed in this study are available from the corresponding author upon reasonable request.

\section{Funding}

This study was partly supported by the Ministry of Education, Culture, Sports, Science and Technology (MEXT) of Japan, under its Earthquake and Volcano Hazards Observation and Research Program. This study was also partly supported by the MEXT KAKENHI Grant JP18K19952, JP18K18777.

\section{Publisher's Note}

Springer Nature remains neutral with regard to jurisdictional claims in published maps and institutional affiliations. 
Received: 3 February 2019 Accepted: 6 April 2019

Published online: 27 April 2019

\section{References}

Geospatial Information Authority of Japan (2018a) Crustal strain in Hokkaido region (100 years: 1883-1994). http://www.gsi.go.jp/cais/HIZUMI-hizum i1-100.html. Accessed 25 Dec 2018 (in Japanese)

Geospatial Information Authority of Japan (2018b) The 2018 Hokkaido Eastern Iburi earthquake: fault model (preliminary). http://www.gsi.go.jp/cais/ topic180912-index-e.html. Accessed 25 Dec 2018 (in Japanese)

Hasegawa A, Nakajima J, Umino N, Miura S (2005) Deep structure of the northeastern Japan arc and its implications for crustal deformation and shallow seismic activity. Tectonophysics 403(1-4):59-75. https://doi.org/10.1016/j. tecto.2005.03.018

Hashinoto M, Tada T (1988) Horizontal crustal movements in Hokkaido and its tectonic implications. Zisin 41:29-38. https://doi.org/10.4294/zisin 1948.41.1_29 (in Japanese with English abstract)

Headquarters for Earthquake Research Promotion (2018a) Evaluation of the 2018 Hokkaido Eastern Iburi Earthquake. https://www.jishin.go.jp/main/ index-e.html. Accessed 6 Dec 2018

Headquarters for Earthquake Research Promotion (2018b) Long term evaluation of active faults: Ishikari-Teichi-Toen fault zone. https://www.jishin.go jp/main/chousa/katsudansou_pdf/06_ishikari-teichi_2.pdf. Accessed 22 Jan 2019 (in Japanese)

lio Y, Sagiya T, Kobayashi Y (2004) Origin of the concentrated deformation zone in the Japanese Islands and stress accumulation process of intraplate earthquakes. Earth Planets Space 56(8):831-842. https://doi.org/10.1186/ BF03353090

Iwasaki T, Adachi K, Moriya T, Miyamachi H, Matsushima T, Miyashita K, Takeda T, Taira T, Yamada T, Ohtake K (2004) Upper and middle crustal deformation of an arc-arc collision across Hokkaido, Japan, inferred from seismic refraction/wide-angle reflection experiments. Tectonophysics 388(1-4):59-73. https://doi.org/10.1016/j.tecto.2004.03.025

Kimura G (1994) The latest cretaceous-early Paleogene rapid growth of accretionary complex and exhumation of high pressure series metamorphic rocks in northwestern Pacific margin. J Geophys Res 99(B11):2214722164. https://doi.org/10.1029/94JB00959

Kimura G (1996) Collision orogeny at arc-arc junctions in the Japanese Islands. Island Arc 5(3):262-275. https://doi.org/10.1111/j.1440-1738.1996.tb000 31.x

Kita S, Hasegawa A, Nakajima J, Okada T, Matsuzawa T, Katsumata K (2012) High-resolution seismic velocity structure beneath the Hokkaido corner, northern Japan: arc-arc collision and origins of the 1970 M 6.7 Hidaka and 1982 M 7.1 Urakawa-oki earthquakes. J Geophys Res 117:B12301. https://doi.org/10.1029/2012jb009356
Loveless JP, Meade BJ (2010) Geodetic imaging of plate motions, slip rates, and partitioning of deformation in Japan. J Geophys Res 115:B02410. https:// doi.org/10.1029/2008JB006248

Meneses-Gutierres A, Sagiya T (2016) Persistent inelastic deformation in central Japan revealed by GPS observation before and after the Tohoku-oki earthquake. Earth Planet Sci Lett 450:366-371. https://doi.org/10.1016/j. epsl.2016.06.055

Meneses-Gutierres A, Sagiya T, Sekine S (2018) Crustal deformation process in the Mid-Niigata region of the Niigata-Kobe tectonic zone as observed by dense GPS network before, during, and after the Tohoku-oki earthquake. J Geophys Res 123(7):6072-6085. https://doi.org/10.1029/2018JB015567

Miura S, Sato T, Hasegawa A, Suwa Y, Tachibana K, Yui S (2004) Strain concentration zone along the volcanic front derived by GPS observations in NE Japan arc. Earth Planets Space 56:1347-1355. https://doi.org/10.1186/ BF03353360

Nakagawa H, Toyofuku T, Kotani K, Miyahara B, Hatanaka Y, Munekane H, Ishimoto S, Yutsudo T, Ishikura N, Sugawara Y (2009) Development and validation of GEONET new analysis strategy (version 4). J Geogr Surv Inst 118:1-8 (in Japanese)

Nakata T, Imaiuzmi T (eds) (2002) Digital active fault map of Japan. University of Tokyo Press, Tokyo, p 60 (in Japanese)

National Institute of Advanced Industrial Science and Technology (2018) GALILEO: gravity anomalies leaning online. https:/gbank.gsj.jp/gravdb/ index.php. Accessed 7 Dec 2018

National Research Institute for Earth Science and Disaster Resilience (2018) F-net earthquake mechanism information. http://www.fnet.bosai.go.jp/ fnet/event/joho.php?LANG=en. Accessed 27 Dec 2018

Ohzono M, Yabe Y, linuma T, Ohta Y, Miura S, Tachibana K, Sato T, Demachi T (2012) Strain anomalies induced by the 2011 Tohoku earthquake (Me9.0) as observed by a dense GPS network in northeastern Japan. Earth Planets Space 64:17. https://doi.org/10.5047/eps/2012.05/015

Ozawa S, Kaidzu M, Murakami M, Imakiire T, Hatanaka Y (2004) Coseismic and postseismic crustal deformation after the Mw 8 Tokachi-oki earthquake in Japan. Earth Planets Space 56(7):675-680. https://doi.org/10.1186/BF033 52530

Pollitz FF, Bürgmann R, Banerjee P (2011) Geodetic slip model of the 2011 M9.0 Tohoku earthquake. Geophys Res Lett 38(7):L00G08. https://doi. org/10.1029/2011 gl048632

Sagiya T, Miyazaki S, Tada T (2000) Continuous GPS array and present-day crustal deformation of Japan. Pure Appl Geophys 157(11-12):2303-2322. https://doi.org/10.1007/PL00022507

Shen Z-K, Jackson DD, Ge BX (1996) Crustal deformation across and beyond the Los Angeles basin from geodetic measurements. J Geophys Res 101(B12):27957-27980. https://doi.org/10.1029/96JB02544

Wessel P, Smith WHF, Scharroo R, Luis JF, Wobbe F (2013) Generic Mapping Tools: improved version released. EOS Trans AGU 94:409-410. https://doi. org/10.1002/2013EO450001

\section{Submit your manuscript to a SpringerOpen ${ }^{\circ}$ journal and benefit from:}

- Convenient online submission

- Rigorous peer review

- Open access: articles freely available online

- High visibility within the field

- Retaining the copyright to your article

Submit your next manuscript at $\boldsymbol{\nabla}$ springeropen.com 